Çukurova Üniversitesi Mühendislik Fakültesi Dergisi, 36(3), ss. 649-657, Eylül 2021

Cukurova University Journal of the Faculty of Engineering, 36(3), pp. 649-657, September 2021

\title{
Dört Noktalı Eğme Testi Altında Yapıştırıcı ile Birleştirilmiş Bindirme Bağlantısının Deneysel ve Sonlu Elemanlar Analizi
}

\author{
Salih AKPINAR ${ }^{1}$, Ahmet ÇALIK ${ }^{* 2}$ \\ ${ }^{1}$ Erzurum Teknik Üniversitesi, Mühendislik ve Mimarlık Fakültesi, Makine Mühendisliği \\ Bölümü, Erzurum \\ ${ }^{2}$ Mersin Üniversitesi, Teknik Bilimler Meslek Yüksekokulu, Makine ve Metal Teknolojileri \\ Bölümü, Mersin
}

Geliş tarihi: 16.06.2021

Kabul tarihi: 13.09 .2021

Öz

Yapıştırıcı ile birleştirilmiş bağlantıların kullanımı otomotiv ve havacılık sektörlerinde oldukça yaygındır. Korozyona dayanıklılığı, titreşim absorbe yeteneği ve düşük kütleye sahip olması yapıştırıcıların bağlantılarda sıkça tercih edilmelerinin başlıca nedenleri olarak sıralanabilir. Bu çalışmada, yapıştırılarak bağlanan bindirme bağlantılar üzerinde dört noktalı eğme testi deneysel ve sayısal olarak incelenmiştir. Deneysel çalışmada bindirme uzunluğu ve yapışkan kalınlığı sabit 5 farklı geometrideki numunelere 9 faklı konumda bükme yüklemesi uygulanmıştır. Deneysel çalışmadan kullanılan numunelerin sonlu eleman modelleri ANSYS yazılımında aynı yükleme şartlarında analiz edilmiş ve soyulma ve kesme gerilmeleri bindirme uzunluğu boyunca elde edilmiş ve deneysel sonuçlar sonlu elemanlar sonuçları ile doğrulanmıştır. Mevcut çalışma gösteriyor ki yapıştırıcı ile birleştirilmiş bağlantılarda bükme yükünün konumu test sonuçlarına belli oradan etki etmektedir.

Anahtar Kelimeler: Dört noktalı eğme, Yapıştırma, Bindirme bağlantı, Sonlu elemanlar

\section{Experimental and Finite Element Analysis of Adhesive Bonded Lap Joint Subjected to Four-Point Bending Test}

\begin{abstract}
The use of adhesive bonded joints is very common in the automotive and aerospace industries. Corrosion resistance, vibration absorbing ability and low mass can be listed as the main reasons why adhesives are frequently preferred in connections. In this study, the four-point bending test on glued lap joints was investigated experimentally and numerically. In the experimental study, bending loading was applied to the specimens in 5 different geometries with fixed overlap length and adhesive thickness at 9 different positions. The finite element models of the samples used in the experimental study were analyzed in the ANSYS software under the same loading conditions and the peeling and shear stresses were obtained along the overlap length and the experimental results were verified with the finite element results. The present study shows that the position of the bending load in adhesively bonded joints has a certain effect on test results.
\end{abstract}

Keywords: Four-point bend, Adhesive, Lap joint, Finite elements

\footnotetext{
*Sorumlu yazar (Corresponding author): Ahmet ÇALIK, ac@mersin.edu.tr
} 
Dört Noktalı Ĕğme Testi Altında Yapıştırıcı ile Birleştirilmiş Bindirme Bağlantısının Deneysel ve Sonlu Elemanlar Analizi

\section{GíRiș}

Yapıştırıcı ile birleştirilmiş bağlantılar cıvatalı ve perçinli bağlantılar gibi diğer geleneksel mekanik birleştirme sistemlerine göre montaj avantajlarından dolayı birçok tasarımcı tarafından tercih edilmektedir [1,2]. Yapıştırıcı teknolojisi üzerine yapılan iyileştirmelere paralel olarak Yapıştırıcı ile birleştirilmiş bağlantıların özellikle havacilık ve otomotiv endüstrisindeki uygulama alanı her geçen gün daha da artmaktadır $[3,4]$. Yapıştırıc1 bağlantıların bu popülerliği tasarımcıların ve bilim adamlarının dikkatini daha da çok çekmekte ve yapıştırıcı bağlantılar üzerine yapılan çalışmalara hızla artan bir ilgi sağlayarak bu konudaki çalışmaların güncelliğini korumaktadır.

Yapıştırma bağlantılarda büyük gerilme konsantrasyonunu azaltmak için pek çok yöntem araştırılmaya devam etmektedir. Kademeli bindirme [5], uç doldurma [6], uç dalgalı [7], nano partikül takviyesi [8], köşe yuvarlama [9] ve çift yapışkanların [10] uygulamaları bu yöntemlerin örnekleridir. Gerilme konsantrasyonlarını yaygın olarak inceleyen testler; çekme, kayma, soyulma, kırılma tokluğu ve ayrılma testleridir. Literatürde dört nokta ve üç nokta eğilme testlerine ilişkin çalışmalar yer almaktadır.

Temiz [11] yaptığı çalışmada eğilme momentine maruz kalan çift bantlı bağlantılarda bindirme uzunluğu boyunca farklı rijitliklere sahip iki yapıştırıcının uygulanmasını ve kademeli rijitliğe sahip bağlantı hatlarının kullanılmasıyla bağlantı mukavemetinde olası kazanımlarını incelemiştir.

Eğilme momentine maruz kalan yapıştırıcıyla birleştirilmiş tek bindirmeli bağlantı üzerindeki püskürme dolgusunun etkisi incelemek için çeşitli genişliklerdeki tek bindirmeli bağlantıların mekanik davranışları deneysel ve sayısal olarak Akpınar ve arkadaşları [12] tarafından incelenmiştir.

Aydın ve arkadaşları [13] yaptığı çalışmada yapıştırıcıların (FM 73 ve SBT 9244) performansını değerlendirmek için farklı bindirme uzunluklarına sahip derzler üzerinde dört noktadan bükme deneyleri yapılmış ve bindirme bağlantıların kırılma yüzeyleri Taramalı Elektron Mikroskobu (SEM) ile incelenmiştir. Bindirme bağlantılarda, yapıştırıcıların ve yapıştırılanların gerilme-gerinim davranışları (AA2024-T3) dikkate alınarak doğrusal olmayan sonlu elemanlar yöntemi ile gerilme analizi yapıldıktan sonra, nümerik sonuçları deneysel sonuçlar ile doğrulanmıştır.

Tran ve arkadaşları [14] parmak eklem direncini artırmak için, Dört noktalı eğme testlerinden elde edilen maksimum eğilme kuvvetini dikkate alıp tasarım değişkenleri olarak tanımladıkları uzunluğu, eğim ve uç boşluklarını Yanıt Yüzey Yöntemi ve Kriging interpolasyonu kullanılarak optimize etmişlerdir.

Akpınar, I. ve arkadaşları [15] yaptığı çalışmada; nano takviyeli yapışkanlı tek bindirmeli kompozit bağlantıların çekme ve dört nokta eğilme yükleri altındaki yüklerine, çekme ve eğilme momenti hasar mekanizmaları ve yer değiştirme yeteneği deneysel olarak belirlendi.

Bir başka çalışmada, epoksi yapıştırıcı Araldite 2015'e GNP-OH ve nano silika partiküllerinin eklenmesinin etkisi, alüminyumun dört noktadan bükülmeye maruz kalan kompozit bağlı bindirme bağlantılarına yorulma davranışı üzerinde incelenmiştir [16].

Bu çalışmada, yapıştırıcı ile birleştirilmiş bindirme bağlantılar üzerinde dört noktalı eğme testi 9 faklı modelde deneysel ve sayısal olarak incelenmiştir. Yükleme noktalarının deney sonuçlarına ne tür etkiler yaptığı araştırılmıştır. Sonuçlar gösteriyor ki yükleme noktalarının konumları pek çok modelde sonuçları etkilemese de L1 uzunluğunun bindirme uzunluğunun yarısından az olduğu durumlarda L2 uzunluğunun önemli bir etken olduğu sonucuna varılmıştır.

\section{MATERYAL VE METOT}

\subsection{Malzeme ve Numuneler}

Yapıştırılarak bağlanan tek tesirli bindirme bağlantı numuneleri, $\quad 3.0 \mathrm{~mm}$ kalınlığında 
alüminyum AA2024-T3 tabakalardan oluşmuştur. AA2024-T3 alüminyum alaşımı havacılık sektöründe yaygın kullanıma sahiptir. Alüminyum tabakaları yapıştırmak için iki parçalı bir epoksi yapıştırıcı, DP460 (3M $\left.\mathrm{M}^{\mathrm{TM}}\right)$ kullanıldı. Epoksi ve hızlandırıcıdan oluşan çift bileşenli DP460 yapışkanı, deneylerde epoksi hızlandırıcının iki katı olacak şekilde karıştırılarak kullanılmıştır. DP460 yapıştırıcısı metallerin yanı sıra cam, seramik ve pek çok kompozit malzemelerin birleştirilmesinde kullanılır. Bu yapıştırıcı dinamik yüklere karşı yüksek direnç sağlar. Otomotiv ve denizcilik (gemi yapımında) sektörü gibi büyük boyutlu metal ve kompozit parçaların yapıştırılmasında düşük maliyetli bir bağlantı sağlaması başlıca avantajıdır.

Bağlantıda kullanılacak alüminyum levhalar $3 \mathrm{~mm}$ kalınlığında ve Çizelge 1'de boyutlarında hassas testere ile kesildi. İstenilen boyutlarda kesilen levha üzerindeki temizlik işlemleri için kaba zımpara (400'lük SiC) ile zımparalanmıştır. Hassa zımpara (1000'lik ZiC) ile kaba zımpara ile temizlenmiş numune üzerindeki kaba zımpara çizikleri yok edilmiştir. İki aşamalı zımpara işlemi neticesinde numunelerde temiz ve pürüzsüz yüzeyler elde edilmiştir. Pürüzsüz yüzeye sahip numuneler toz deterjan ile yıkanmış ve sonrasında asetonda 10-12 dakika bekletilmiştir. Daha sonra numuneler $60^{\circ} \mathrm{C}$ sıcaklıkta bir etüv içerisinde kurutulmuşlardır.

Yüze hazırlama işlemi tamamlanmış numunelerin bindirme bölgelerine sıvı yapıştırıcı bir mastar yardımıyla yayılmıştır. Yapışkan kalınlı 0,18 mm kalınlığında tüm yapışma bölgesince sabit kalabilmesi için bağlantının her iki ucuna 3,18 mm kalınlığında metal parçalar kullanılarak, sabitleme kalıplarının (Şekil 1) içerisine yerleştirilmiştir. Kalıp içerisindeki numuneler oda sıcaklığında 12 saat boyunca $70^{\circ} \mathrm{C}$ ve $0,15 \mathrm{MPa}$ basinç ile kürlendi. Kürleşme sonrası numuneler 12 saat boyunca oda sıcaklığında soğumaya birakılarak tam kürleşme sağlanmıştır. Yapıştırılan numuneler kalıptan çıkarıldıktan sonra keski bir bıçak yardımıyla dışarı taşarak fazlalık oluşturan donmuş yapışkanlar temizlenmiştir. Böylece deneysel çalışmadan kullanılacak numuneler elde edilmiştir (Şekil 2).

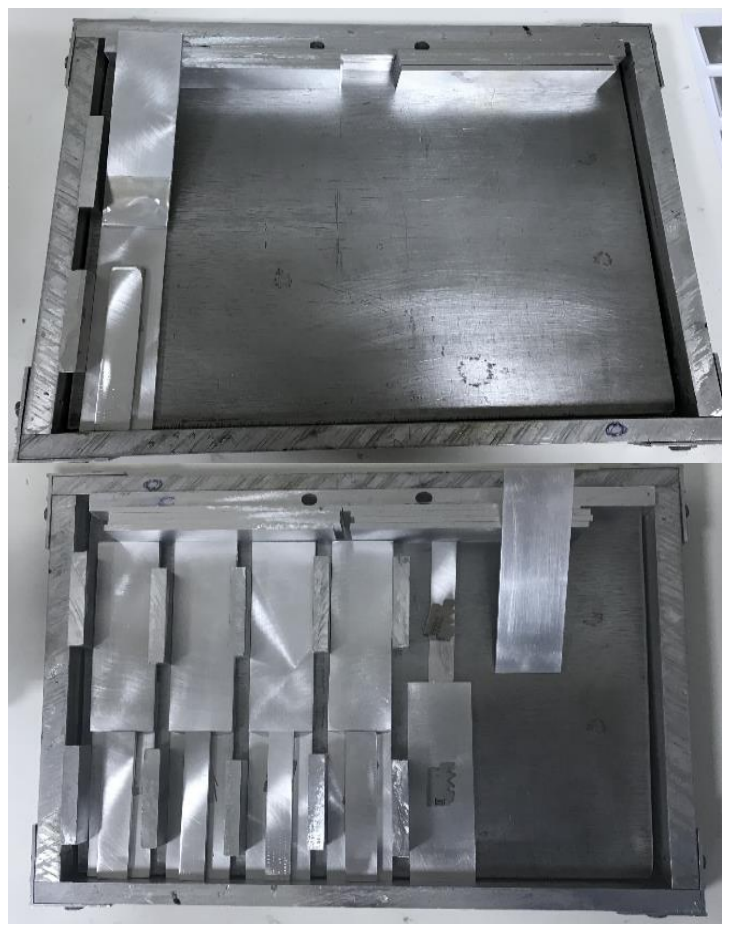

Şekil 1. Yapıştırma bağlantı için sabitleme kalıbı

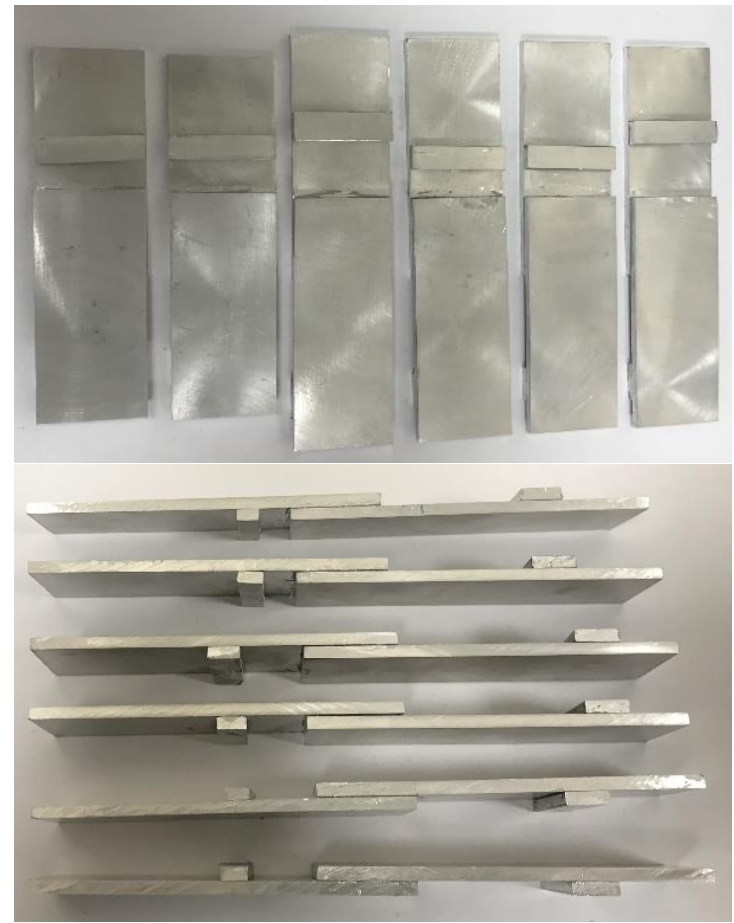

Şekil 2. Deneysel numuneler 
Dört Noktalı Ĕ̆me Testi Altında Yapıştırıcı ile Birleştirilmiş Bindirme Bă̆lantısının Deneysel ve Sonlu Elemanlar Analizi

\subsection{Deneysel Prosedür}

Bu çalışmada, farklı yükleme noktalarında eğme momentine maruz yapıştırma ile birleştirilmiş bindirme bağlantılarında maksimum yerdeğiştirme ve eğilme momenti kopma yükü incelenmiştir. Yapıştırılan levha üzerindeki yükleme noktalarının konumları (L1 ve L2 uzunlukları, Şekil 1) değiştirilirken sonuçları doğru bir şekilde karşılaştırmak için, bindirme uzunluğu, yapışkan ve levha kalınlığı sabit tutuldu. Bu örneklerin deneysel ve geometrik parametreleri Çizelge 1 ve Şekil 3'de verilmiştir.
Çizelge 1. Dört nokta eğme testine maruz yapıştırma ile birleştirilmiş bağlantının yükleme parametreleri

\begin{tabular}{|c|c|c|}
\hline Yükleme Tipi & $L_{1}(\mathrm{~mm})$ & $L_{2}(\mathrm{~mm})$ \\
\hline YT-1 & 30 & 10 \\
\hline YT-2 & 30 & 20 \\
\hline YT-3 & 30 & 30 \\
\hline YT-4 & 20 & 10 \\
\hline YT-5 & 20 & 20 \\
\hline YT-6 & 20 & 30 \\
\hline YT-7 & 10 & 10 \\
\hline YT-8 & 10 & 20 \\
\hline YT-9 & 10 & 30 \\
\hline
\end{tabular}

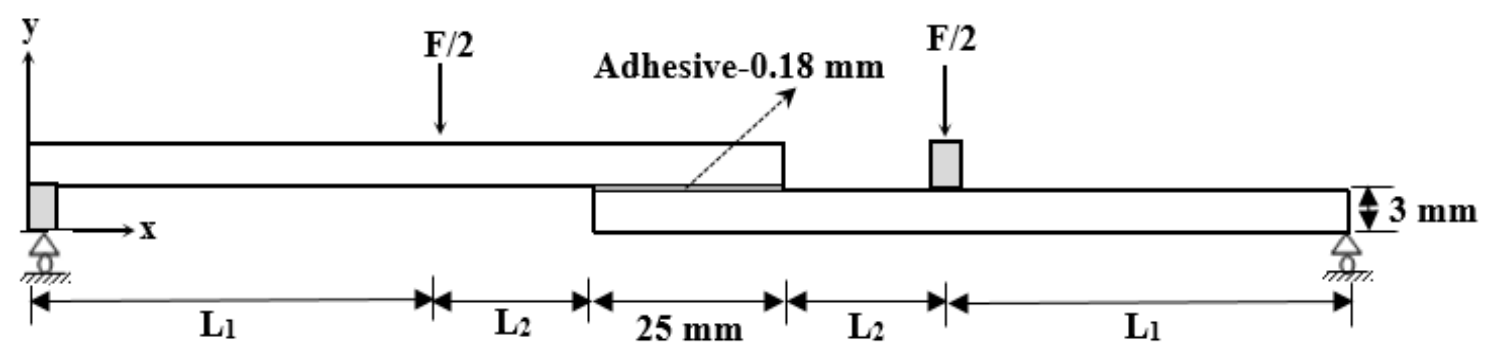

Şekil 3. Dört nokta eğme testine maruz yapıștırma ile birleştirilmiş bağlantının yükleme ve destek pozisyonları

Instron evrensel test makinesinde yapıştırılarak birleştirilen bağlantı numunelerinin eğilme davranışlarını belirlemek için dört noktalı eğme deneyleri yapıldı. Deney numuneleri iki sabit destek üzerine bindirildi, yük yapışma uzunluğunu merkezleyecek şekilde iki noktadan Şekil 3'de gösterildiği gibi uygulandı. Test cihazı çenelerinin kafa hızı, ASTM D 790-07 standardına göre $5 \mathrm{~mm} /$ dak idi. Üst üste bindirme bağlantıya sahip olmaları nedeniyle numunelerin sol ve sağ tarafları, test destekleri üzerinde yatay olarak konumlandırılamaz. Bunun üstesinden gelmek için, uygun kalınlığa sahip ek plakalar (destekler) test numunesinin sağ veya sol tarafının altına yerleştirildi. Ayrıca yükün uygulandığı noktalara yapışma yüzeyine momentin eşit dağılmasını sağlamak için yükün uygulandığı noktalara yatay konumlandırma olacak şekilde destek elemanları yerleştirilmiştir. Dört noktadan bükme test ekipmanı ve örnek yük konumlandırması Şekil 4'de gösterilmektedir.

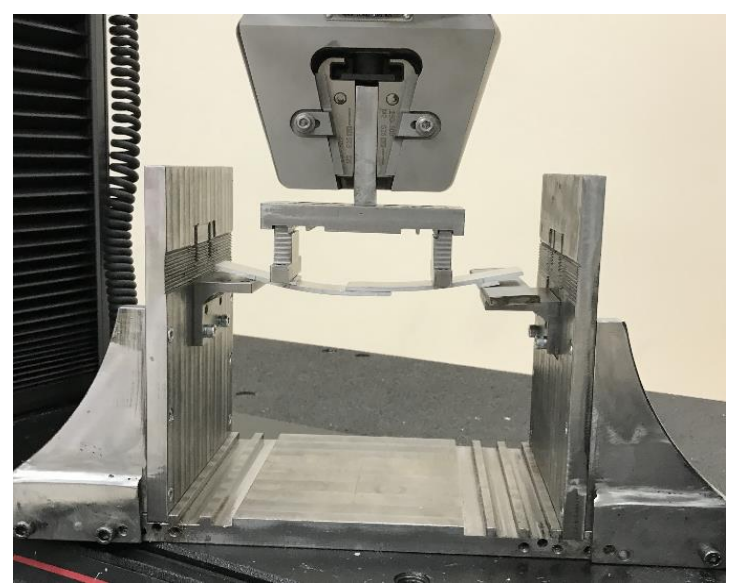

Şekil 4. Dört noktadan bükme test ekipmanı ve örnek yük konumlandırması

Tüm ortak numuneler için uygulanan yük aynı fakat yükün konumları farklıdır. Her bir test en az 3 kez tekrarlandı. Doğrulanmış sonuçlar kaydedilerek hasar yükleri Çizelgesi oluşturulmuştur (Çizelge 2). 
Çizelge 2. Numunelerin deneysel sonuçları

\begin{tabular}{|c|c|c|c|c|}
\hline $\begin{array}{c}\text { Yükleme } \\
\text { Tipi }\end{array}$ & $\begin{array}{c}\text { Moment } \\
\left(\mathrm{F} / 2 * \mathrm{~L}_{1}\right)\end{array}$ & $\begin{array}{c}\text { Experimental failure load, } \\
F_{\text {EXP }}(\mathrm{N})\end{array}$ & $\begin{array}{c}\text { Experimental failure moment, } \\
M_{\text {EXP }}(\mathrm{N} . \mathrm{mm})\end{array}$ & $\begin{array}{c}\text { Displacement } \\
(\mathrm{mm})\end{array}$ \\
\hline YT-1 & $15 \mathrm{~F}$ & 1307 & 19600 & 7,39 \\
\hline YT-2 & $15 \mathrm{~F}$ & 1333 & 19995 & 7,75 \\
\hline YT-3 & $15 \mathrm{~F}$ & 1700 & 25500 & 10,52 \\
\hline YT-4 & $10 \mathrm{~F}$ & 2050 & 20500 & 3,70 \\
\hline YT-5 & 10F & 2260 & 22600 & 5,75 \\
\hline YT-6 & $10 \mathrm{~F}$ & 2650 & 26500 & 2,69 \\
\hline YT-7 & $5 \mathrm{~F}$ & 5681 & 28405 & 5,08 \\
\hline YT-8 & $5 \mathrm{~F}$ & 6361 & 31805 & 3,75 \\
\hline YT-9 & $5 \mathrm{~F}$ & 4803 & 24015 & \\
\hline
\end{tabular}

\subsection{Sonlu Elemanlar Analizi}

Yapıştırıcının (DP460) mekanik özellikleri ve daha önce yayınlanan Akpınar [17]'ın çalışmalarından alınmıştır. Analizde yapıştırıcının mekanik özellikleri; Elastisite modülü $72,400 \pm 530 \mathrm{MPa}$, Poission oran $10,33, \sigma_{\mathrm{t}}: 482 \pm 12 \mathrm{MPa}, \varepsilon_{\mathrm{t}}: 0,1587$, yapıştırılan levhanın mekanik özellikleri ise Elastisite modülü $2077 \pm 47 \mathrm{MPa}$, Poission oranı $0,38, \quad \sigma_{\mathrm{t}}:(\mathrm{MPa}) \quad 44,6 \pm 1,2, \quad \varepsilon_{\mathrm{t}}: 0,0428 \quad$ olarak tanımlanmıştır. Yapılan sonlu eleman ağında eleman boyunu 0,05 mm'den küçük olarak seçilmişmiştir. Stres dağılımının kritik olduğu bölgelerde daha küçük elemanlar kullanılmıştır (Şekil 5). Sınır şartları Şekil 3'de gösterildiği tanımlanmıştır. Yapışma yüzeyinde soyulma ve kesme gerilmesi değerleri rapor edilmiştir.

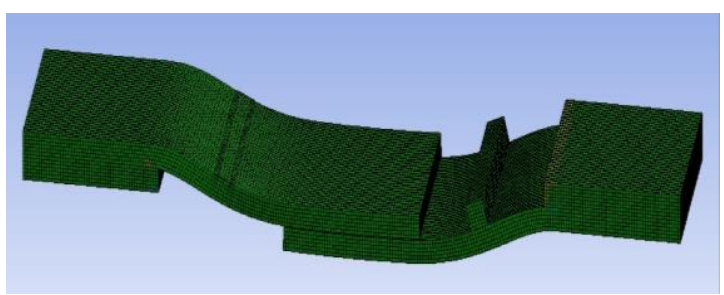

Şekil 5. Bir numuneye ait sonlu eleman ağ modeli

\section{BULGULAR VE TARTIŞMA}

Tek tesirli bindirme bağlantı numuneleri dokuz farklı dört nokta eğme testine maruz bırakılmış olup, her bir yükleme tipine ait maksimum hasar yükü ve bu hasar yüküne tekabül eden yer değiştirme sonuçları Çizelge 2'de verilmiştir. Ayrıca Şekil 6'da verilen yapıştırma bağlantısında oluşan moment eğrisi göz önüne alınarak her bir yükleme tipinde oluşan hasar moment değerleri elde edilmiştir (Çizelge 2).

$L_{1}$ uzunluğunu $30 \mathrm{~mm}$ 'de sabit tutup (YT-1); $\mathrm{L}_{2}$ uzunluğunu 10 mm'den 20 mm'ye çıkardığımızda hasar yükü yaklaşık \%2, $L_{2}$ uzunluğunu 20 mm'den 30 mm'ye çıkardığımızda hasar yükü yaklaşık \%27 ve $L_{2}$ uzunluğunu $10 \mathrm{~mm}$ 'den 30 mm'ye çıkardığımızda hasar yükü yaklaşık $\% 30$ artmaktadir. Ayrica, $L_{1}$ uzunluğunu 20 mm'de sabit tutup (YT-4); $\mathrm{L}_{2}$ uzunluğunu 10 mm'den 20 mm'ye çıkardığımızda hasar yükü yaklaşık \%10, $L_{2}$ uzunluğunu 20 mm'den 30 mm'ye çıkardığımızda hasar yükü yaklaşık $\% 17$ ve $L_{2}$ uzunluğunu $10 \mathrm{~mm}$ 'den $30 \mathrm{~mm}$ 'ye çıkardığımızda hasar yükü yaklaşık \%29 artmaktadır.

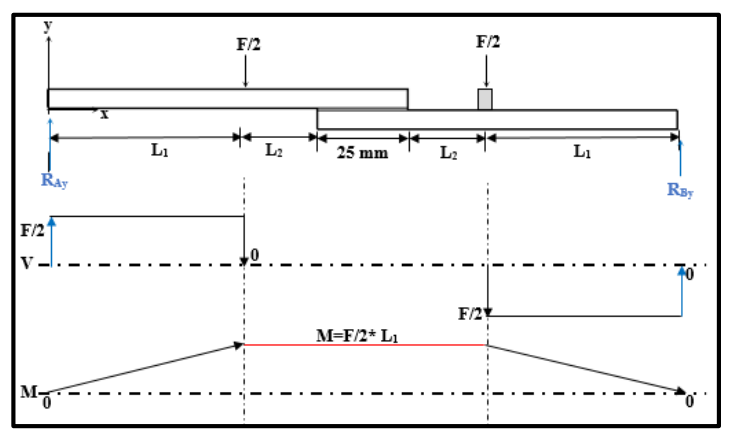

Şekil 6. Dört nokta eğme testine maruz yapıştırma bağlantısında oluşan kesme kuvveti ve moment eğrileri

Diğer taraftan, $L_{1}$ uzunluğunu $10 \mathrm{~mm}$ 'de sabit tutup (YT-7); $\quad \mathrm{L}_{2}$ uzunluğunu 10 mm'den 

Analizi

20 mm'ye çıkardığımızda hasar yükü yaklaşık $\% 12$ artarken, $L_{2}$ uzunluğunu 20 mm'den 30 mm'ye çıkardığımızda hasar yükü yaklaşık $\% 25$ ve $L_{2}$ uzunluğunu $10 \mathrm{~mm}$ 'den $30 \mathrm{~mm}$ 'ye çıkardı̆̆ımızda hasar yükü yaklaşık \%16 azalmaktadır.

Burada elde edilen önemli sonuçlardan biri, YT-1, YT-2 ve YT-3 yükleme tiplerinin bindirme bölgesinde oluşan maksimum moment, $\mathrm{L}_{1}$ 'in sabit olmasından dolayı teorik olarak sabit $15 \mathrm{~F}$ kadar olmaktadır. Ancak L2'nin değişmesi bağlantının hasar yükünün değiştirdiği ve buda maksimum moment değerini değiştirmektedir. Bunun nedeni $\mathrm{L}_{2}$ 'nin artırılması bağlantının eğilme rijitliğini azalttığı ve bu durum bağlantı üzerine gelen yükü sönümleme kapasitesini artırmaktadır. Bu durum sonlu elemanlar analiz yöntemi kullanılarak yapışma yüzeyinden elde edilen soyulma gerilme grafikleri ile oldukça uyumludur (Şekil 8).

$L_{2}$ uzunluğunu 10 mm'de sabit tutup $L_{1}$ uzunluğunu $30 \mathrm{~mm}$ 'den $20 \mathrm{~mm}$ 'ye indirdiğimizde, bağlantının hasar yükü yaklaşık \%57, $L_{1}$ uzunluğunu 20 mm'den 10 mm'ye indirdiğimizde bağlantının hasar yükü yaklaşık \%177 ve $L_{1}$ uzunluğunu 30 mm'den 10 mm'ye indirdiğimizde ise bağlantının hasar yükü yaklaşık \%335 artmaktadir. $\mathrm{L}_{1}$ uzunluğunun azaltılması bağlantının bindirme bölgesinde oluşan maksimum momenti sirasiyla $15 \mathrm{~F}, 10 \mathrm{~F}$ ve $5 \mathrm{~F}$ 'e kadar düşürmekte ve bu durum bağlantının hasar yükünü artırmaktadır. Ancak buradan elde edilen önemli sonuçlardan biri, $\mathrm{L}_{1}$ uzunluğuna bağlı olarak bağlantıda oluşan teorik moment deki azalma oranına göre bağlantının hasar yükündeki artış oranı teorik olarak beklenenden daha fazla olmaktadır. Bu durum uzunluğa bağlı olarak bağlantıda oluşan eğilme rijitliği ile ilişkilidir.

Ayrıca, $L_{2}$ uzunluğunu $20 \mathrm{~mm}$ 'de sabit tutup $L_{1}$ uzunluğunu $30 \mathrm{~mm}$ 'den $20 \mathrm{~mm}$ 'ye indirdiğimizde, bağlantının hasar yükü yaklaşık \%70, $L_{1}$ uzunluğunu $20 \mathrm{~mm}$ 'den $10 \mathrm{~mm}$ 'ye indirdiğimizde bağlantının hasar yükü yaklaşık $\% 181$ ve $L_{1}$ uzunluğunu 30 mm'den 10 mm'ye indirdiğimizde bağlantının hasar yükü yaklaşık \%377 artmaktadır. Diğer taraftan $L_{2}$ uzunluğunu 20 mm'de sabit tutup $L_{1} \quad$ uzunluğunu 30 mm'den 20 mm'ye indirdiğimizde, bağlantının hasar yükü yaklaşık $\% 56, \quad L_{1}$ uzunluğunu $20 \mathrm{~mm}$ 'den $10 \mathrm{~mm}$ 'ye indirdiğimizde bağlantının hasar yükü yaklaşık $\% 81$ ve $L_{1}$ uzunluğunu $30 \mathrm{~mm}$ 'den $10 \mathrm{~mm}$ 'ye indirdiğimizde bağlantının hasar yükü yaklaşık $\% 183$ artiyor. Bu deneysel verilerden elde edilen önemli sonuçlardan bir diğeri ise, dört nokta eğme yüküne maruz bağlantının hasar yükü açısından $L_{1}$ uzunluğuna göre $L_{2}$ uzunluğunun daha etkili olmasıdır. Ayrıca bağlantı hasar yükü açısından en iyi sonuç $L_{1}$ uzunluğunun $10 \mathrm{~mm}$ ve $L_{2}$ uzunluğunun $20 \mathrm{~mm}$ olan yükleme tipinden (YT-8) elde edilmiştir.

Yapıştırıcıyla birleştirilmiş tek kademeli bindirme bağlantısında bindirme uzunluğunun ve malzeme kalınlığının yapıştırıcı tabakasında oluşan gerilmeleri nasıl etkilediğini incelemek için, Şekil 7'de gösterilen yapıştırıcı tabakasının genişliğinin orta hattı olan A-B hattı boyunca gerilmeler elde edilmiştir. Yapıștırıcıyla birleştirilmiş bağlantılarda hasara neden olan gerilmeler yapıştırıcı tabakasında oluşan soyulma $\left(\sigma_{\mathrm{y}}\right)$ ve kayma $\left(\tau_{\mathrm{xy}}\right)$ gerilmeleri olduğundan, numerik analizde bu iki gerilme göz önüne alınmıştır. Gerilme dağılımları farklı yükleme tiplerine sahip tüm bağlantılarda 650 N'luk (deneysel olarak elde edilen en küçük hasar yükünün yaklaşık yarısı olan yük) eğme yükü altında incelenmiştir.

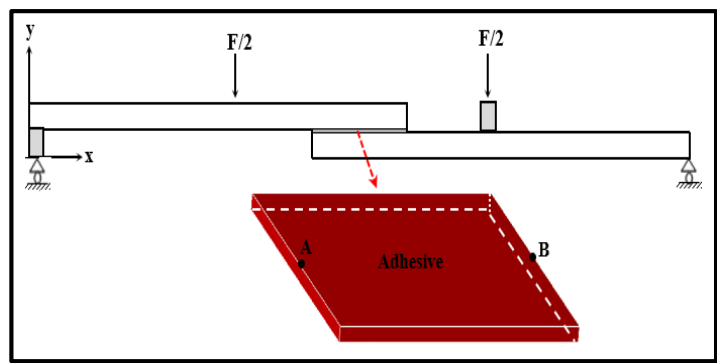

Şekil 7. Tek kademeli bindirme bağlantısının sonuçların alındığı A-B referans hattı

Şekil 8'da verilen farklı yükleme tiplerine sahip tek kademeli bindirme bağlantısının A-B hattı boyunca oluşan soyulma gerilme $\left(\sigma_{\mathrm{y}}\right)$ dağılımları incelendiğinde, bindirme bölgesinin uçlarında soyulma gerilmelerinin yoğunlaştığı ve A noktasında bası karakterli B noktasında ise çeki 
karakterli olduğu görülmektedir. Bu durum dört nokta eğme yüklemesinin sınır şartlarından kaynaklanmaktadır. Bindirme bölgesinin her iki ucundan merkeze doğru yaklaşık \%20 kısımdan sonra soyulma gerilmeleri (merkeze yakın bölgelerde) yaklaşık sıfır olduğu anlaşılmaktadır. Yapıştırma bağlantılarında $L_{1}$ ve $L_{2}$ uzunluklarına bağlı olarak A ve B noktalarında oluşan soyulma gerilmeleri değiștirmektedir. Bindirme bölgesinin uçlarında oluşan bu soyulma gerilmelerinin azalması bağlantının hasar yükünü artmasına neden olacağı varsayımı göz önüne alındığında, deneysel veriler ile nümerik analiz verilerinin birbiriyle oldukça uyumlu olduğu görülmektedir.

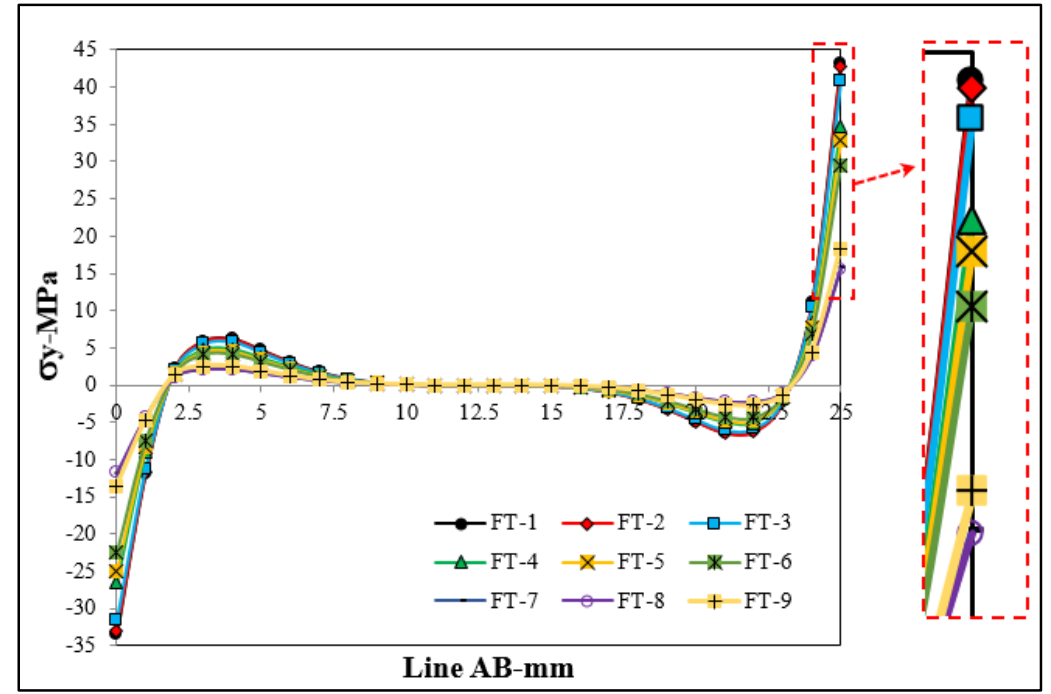

Şekil 8. Farklı yükleme tiplerinde A-B hattı boyunca yapıştırıcı tabakasında oluşan soyulma gerilme $\left(\sigma_{\mathrm{y}}\right)$ dağılımlarının karşılaştırılması

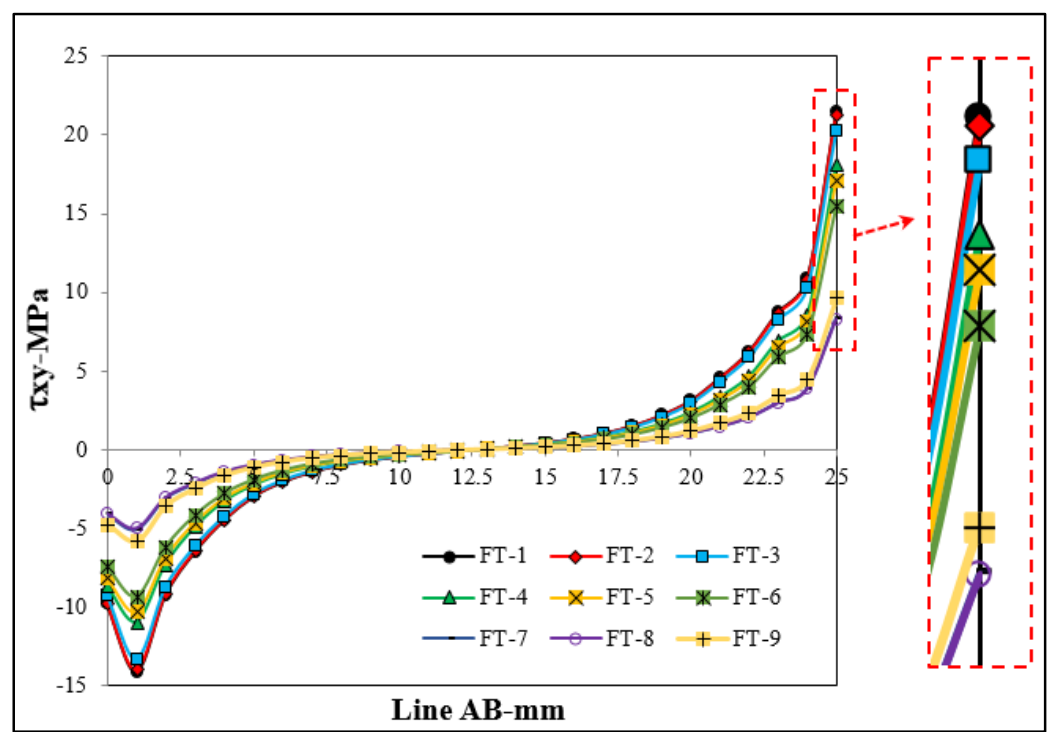

Şekil 9. Farklı yükleme tiplerinde A-B hattı boyunca yapıştırıcı tabakasında oluşan kayma gerilme $\left(\tau_{\mathrm{xy}}\right)$ dağılımlarının karşılaştırılması 
Dört Noktalı Ĕğme Testi Altında Yapıştırıcı ile Birleştirilmiş Bindirme Bağlantısının Deneysel ve Sonlu Elemanlar Analizi

Şekil 9'da verilen kayma gerilmeleri $\left(\tau_{\mathrm{xy}}\right)$ incelendiğinde, bağlantıda $\mathrm{L}_{1}$ uzunluğunun sabit $\mathrm{L}_{2}$ uzunluğunun artmasıyla bindirme bölgesinin B uçunda oluşan gerilme değerinin azaldığı görülmektedir. Ayrıca bindirme bölgesinin uçlarında oluşan hem soyulma hem de kayma gerilme değerindeki azalma en fazla YT-8 olan yükleme tipinde olduğu ve deneylerden elde edilen hasar yükünün en fazla bu yükleme tipinde olmas1, deneysel ve nümerik analizlerin uyumu açısından önemli bir sonuçtur.

\section{SONUÇLAR}

Bu çalışmadan elde edilen sonuçlar aşağıdaki gibi özetlenebilir:

$L_{2}$ 'nin artırılması bağlantının eğilme rijitliğini azalttığı ve bu durum bağlantı üzerine gelen yükü sönümleme kapasitesini artırmaktadır.

$L_{1} \quad$ uzunluğuna bağlı olarak bağlantıda oluşan teorik moment deki azalma oranına göre bağlantının hasar yükündeki artış oranı teorik olarak beklenenden daha fazla olmaktadır. Bu durum uzunluğa bağlı olarak bağlantıda oluşan eğilme rijitliği ile ilişkilidir.

Dört nokta eğme yüküne maruz bağlantının hasar yükü açısından $L_{1}$ uzunluğuna göre $L_{2}$ uzunluğunun daha etkili olmasıdır.

Bağlantı hasar yükü açısından en iyi sonuç $L_{1}$ uzunluğunun $10 \mathrm{~mm}$ ve $L_{2}$ uzunluğunun $20 \mathrm{~mm}$ olan yükleme tipinden (YT-8) elde edilmiştir.

Yapılan çalışmada deneysel veriler ile nümerik analiz verilerinin birbiriyle oldukça uyumlu olduğu gözlemlenmiştir.

\section{KAYNAKLAR}

1. da Silva, L.F.M., Campilho, R.D.S.G., 2012. Advances in Numerical Modelling of Adhesive Joints. Springer Briefs in Applied Sciences and Technology, 1-93.

2. Çalık, A., Akpinar, S., 2019. Effect of Extensometer Usage on Obtaining the Force-
Displacement Curve of the Adhesively Single Lap Joint. European Mechanical Science, 3(4), 142-6. doi: 10.26701/ems.646610.

3. Filipe, L., N.D., 2008. Modeling of Adhesively Bonded Joints. $1^{\text {st }}$ Ed. Editors: da Silva, Lucas F. M. (Ed.) Springer, 335. Doi: 10.1007/978-3540-79056-3.

4. Bayramoglu, S., Akpinar, S., Çalık, A., 2021. Numerical Analysis of Elasto-plastic Adhesively Single Step Lap Joints with Cohesive Zone Models and its Experimental Verification. Journal of Mechanical Science and Technology, 35(2), 641-9. doi: 10.1007/s12206-021-0124-0.

5. Bayramoglu, S., Demir, K., Akpinar, S., 2020. Investigation of Internal Step and Metal Part Reinforcement on Joint Strength in the Adhesively Bonded Joint: Experimental and Numerical Analysis. Theoretical and Applied Fracture Mechanics, 108, 102613. doi: 10.1016/j.tafmec.2020.102613.

6. Tsai, M.Y., Morton, J., 1995. The Effect of a Spew Fillet on Adhesive Stress Distributions in Laminated Composite Single-lap Joints. Composite Structures, 32(1-4), 123-31. doi: 10.1016/0263-8223(95)00059-3.

7. Solmaz, M.Y., Yildirim, S., 2018. Yapıştırıcı ile Birleştirilmiş Dalgalı Bağlantı (Wavy-lap) Performanslarının Uç Açısına Bağlı Olarak Araştırılması. Fırat Üniv. Müh. Bil. Dergisi, 30(1), 287-94.

8. Akpinar, S., 2016. Alüminyum Oksit ve Titanyum Dioksit Partikül Takviyeli Yapıştırıcılarla Birleştirilmiş Bağlantıların Mekanik Özelliklerinin Deneysel Olarak Belirlenmesi. Ömer Halisdemir Üniversitesi, Mühendislik Bilimleri Dergisi, 5(2), 244-52. doi: 10.28948/ngumuh.295635.

9. Çalık, A., 2016. Effect of Adherend Shape on Stress Concentration Reduction of Adhesively Bonded Single Lap Joint. Engineering Review, 36(1), 29-34.

10. Afkar, A., Camari, M.N., 2014. Finite Element Analysis of Mono-and Bi-Adhesively Bonded Functionally Graded Adherend. Journal of Failure Analysis and Prevention, 14(2), 253-8. doi: 10.1007/s11668-014-9790-X.

11. Temiz, Ş., 2006. Application of Bi-adhesive in Double-strap Joints Subjected to Bending 
Moment. Journal of Adhesion Science and Technology, 20(14), 1547-60. doi: 10.1163/156856106778884262.

12. Akpinar, S., Doru, M.O., Özel, A., Aydin, M.D., Jahanpasand, H.G., 2013. The Effect of the Spew Fillet on an Adhesively Bonded Single-lap Joint Subjected to Bending Moment. Composites Part B: Engineering, 55, 55-64. doi: 10.1016/j.compositesb.2013.05.056.

13. Demir Aydin, M., Özel, A., Temiz, Ş., 2004. Non-linear Stress and Failure Analyses of Adhesively-bonded Joints Subjected to a Bending Moment. Journal of Adhesion Science and Technology, 18(14), 1589-602. doi: 10.1163/1568561042411286.

14. Tran, V.D., Oudjene, M., Méausoone, P.J., 2014. FE Analysis and Geometrical Optimization of Timber Beech Finger-joint Under Bending Test. International Journal of Adhesion and Adhesives, 52, 40-7. doi: 10.1016/j.ijadhadh.2014.03.007.

15. Akpinar, I.A., Gültekin, K., Akpinar, S., Akbulut, H., Ozel, A., 2017. Research on Strength of Nanocomposite Adhesively Bonded Composite Joints. Composites Part B: Engineering, 126, 143-52. doi: 10.1016/j. compositesb.2017.06.016.

16.Zamani, P., Jaamialahmadi, A., da Silva, L.F.M., 2021. The Influence of GNP and Nano-silica Additives on Fatigue Life and Crack Initiation Phase of Al-GFRP Bonded Lap Joints Subjected to Four-point Bending. Composites Part B: Engineering, 207 (September 2020): $108589 . \quad$ doi: 10.1016/j.compositesb.2020.108589.

17. Gavgali, E., Sahin, R., Akpinar, S., 2021. An Investigation of the Fatigue Performance of Adhesively Bonded Step-lap Joints: An Experimental and Numerical Analysis. International Journal of Adhesion and Adhesives, 104(June 2020): 102736. doi: 10.1016/j.ijadhadh.2020.102736. 
